\title{
Inari Sami Language
}

National Cancer Institute

\section{Source}

National Cancer Institute. Inari Sami Language. NCI Thesaurus. Code C154121.

A Uralic Sami language spoken by the Inari Sami people of Finland. 